\title{
Peripheral Lymphadenopathy: A Descriptive Study from a Tertiary Care Centre in Lubumbashi (D.R.C)
}

\author{
Christian Kakisingi1, Olivier Mukuku², Michel Manika1, Marc Kashal3, Véronique Kyabu', \\ Eric Kasamba ${ }^{4}$, Beya Tshikuluila ${ }^{5}$, Claude Mwamba $^{1}$ \\ ${ }^{1}$ Department of Internal Medicine, School of Medicine, University of Lubumbashi, Lubumbashi, DR Congo \\ ${ }^{2}$ Department of Public Health, School of Medicine, University of Lubumbashi, Lubumbashi, DR Congo \\ ${ }^{3}$ Department of Surgical, School of Medicine, University of Lubumbashi, Lubumbashi, DR Congo \\ ${ }^{4}$ Department of Basics Sciences, School of Medicine, University of Lubumbashi, Lubumbashi, DR Congo \\ ${ }^{5}$ Mafikeng Provincial Hospital, Mafikeng, Republic of South Africa \\ Email: chriskakis@yahoo.fr
}

Received 27 May 2016; accepted 23 June 2016; published 27 June 2016

Copyright (C) 2016 by authors and OALib.

This work is licensed under the Creative Commons Attribution International License (CC BY).

http://creativecommons.org/licenses/by/4.0/

(c) (i) Open Access

\section{Abstract}

Introduction: The causes of superficial lymphadenopathy are diverse and their prognosis is often unknown. The diagnosis of superficial lymphadenopathy remains a challenge because, alone, its clinical picture doesn't allow differentiating between an infectious disease and a non-transmissible disease. The aim of this study is to describe epidemiological, clinical and pathologic aspects of superficial lymphadenopathy observed in the internal medicine department at the University of Lubumbashi Clinics (DR Congo). Patients, Materials and Methods: This is a descriptive and transversal study on superficial lymphadenopathy observed over a period of 24 months from November 2013 to October 2015 at the University of Lubumbashi Clinics. Parameters studied were gender, age, clinical particular of superficial lymphadenopathy and associated patient clinical signs and pathology of these lymph nodes biopsy. Results: 36 patients' data were identified with a sex ratio $M / F=1.76$ and a mean age of $42.47 \pm 15.64$ years. $75 \%$ of patients had lymph nodes tumefaction as the main complaint during consultation and $61.1 \%$ had a poor general condition marked by fever. $\mathbf{2 7 . 8 \%}$ were HIV positive and cervical lymphadenopathy was the most frequent. As for the pathologic diagnosis, non-Hodgkin lymphoma was the most frequent diagnosis $(47.2 \%)$ followed by reactive hyperplasia $(27.8 \%)$ and infectious lymphadenopathy $(19.4 \%)$. Conclusion: The most frequent cause of lymphadenopathy in our study was non-Hodgkin lymphoma $(47.2 \%)$ followed by lymph nodes reactive hyperplasia $(27.8 \%)$ and infectious lymphadenitis. Lymph nodes biopsy plays an important role in confirming superficial lymphadenopathy diagnosis. It should be the basic procedure to diagnose extra pulmonary tuberculosis in the DRC National Program against TB.

\section{Keywords}

Superficial Lymphadenopathy, Epidemiology, Clinic, Aetiology

How to cite this paper: Kakisingi, C., Mukuku, O., Manika, M., Kashal, M., Kyabu, V., Kasamba, E., Tshikuluila, B. and Mwamba, C. (2016) Peripheral Lymphadenopathy: A Descriptive Study from a Tertiary Care Centre in Lubumbashi (D.R.C). Open Access Library Journal, 3: e2771. http://dx.doi.org/10.4236/oalib.1102771 


\section{Introduction}

Lymph nodes are tissues made of specialized cells that play an essential role in the organism defence mechanism [1]. The generic word referring to all lymph nodes disease is lymphadenopathy. This abnormality can be defined by its dimensions, consistency and/or the number of abnormal lymph nodes [2]. The causes of superficial lymphadenopathy are multiple and their prognosis is often unrecognized; and that, whatever their localized or generalized character [3]. Lymphadenopathy is part of symptoms of a wild range of diseases covered under the acronym: "MIAMI" (Malignant, Infectious, Autoimmune, Miscellaneous/unusual, Iatrogenic) [4] for some and "CHICAGO" (Cancer, Hypersensitivity syndromes, Infectious, Connective tissue disorders, Atypical lymphoproliferative disorders, Granulomatous, Others) [5] for others and no prevalence could be determined; however, Fijten has determined prevalence of malignancy in case of superficial lymphadenopathy estimated at $1.1 \%$ [6]. The diagnosis of superficial lymphadenopathy remains a challenge due to the fact that its clinical presentation solely doesn't allow differentiating infectious disease lymphadenopathy from non-transmissible lymphadenopathy disease [7]. Therefore the diagnosis of lymphadenopathy should relay, in low income countries like the Democratic Republic of Congo, on lymph nodes biopsy despite its invasive aspect and highly infectious risk [8]-[12]. Thus, the objective of this study is to describe epidemiological, clinical, and pathologic aspects of superficial lymphadenopathy observed in Internal Medicine Department of the University of Lubumbashi Clinics (DR Congo).

\section{Materials and Method}

\subsection{Type and Study Period}

This is a descriptive and transversal study on patient with superficial lymphadenopathy who had consulted in the department of internal medicine at the University of Lubumbashi Clinics (DR Congo) from 1st November 2013 to 31 October 2015.

\subsection{Study Population}

We have proceeded by a convenience sampling including all patients with superficial lymphadenopathy seen at the internal medicine outpatient department or those admitted in the department of internal medicine at the University of Lubumbashi Clinics where 36 patients were listed.

Were admitted, any patients with hypertrophy affecting one or more palpable superficial lymph nodes in the cervical, axillary or inguinal area, measuring more than one centimeter in diameter, irrespective of the gender. We have retained the age above 15 for our series. Were excluded, all patients on TB treatment and/or on antimitotic treatment.

The study was done using and analyzing patients medical records including sociodemographic parameters (age, gender), clinical description of lymphadenopathy (localization, consistency, mobility, sensibility) and associated signs (fever, visceromegaly), biologic (HIV serology) and histopathologic parameters.

\subsection{Biologic and Histopathogy Analysis}

1) HIV infection diagnosis: HIV serology was determined by a screening rapid test: Determine ${ }^{\mathrm{TM}} \mathrm{HIV}-1 / 2$ (Alere) and positive cases were confirmed by ELISA: Vironostika and Enzygnost done on IMMUNOWASH type WELLWASH 4 MK 2NSERIE 006-9-7943.

2) Bacteriologic analysis of infectious lymphadenopathy: Secretions culture was done on an ordinary microbial culture medium: Sabouraud and Loweisten.

3) Cytopathology analysis: Tissue sampling was done by excision biopsy where the all lymph node tissue is entirely removed under local anesthesia. Once excised the tissue is fixed in formalin $10 \%$ sealed and sent to the pathologist and deposited in plastic cassettes. Tissues contained in plastic cassettes are then dehydrated passed through alcohol (ethanol, isopropanol), alcohol is eliminated by solvents (xylene), and then liquid paraffin at 
$56^{\circ} \mathrm{C}$ impregnates the tissue which is then cooled. These steps are automated by inclusive devices. The solid block of paraffin containing the tissue is cut with a microtome, 3 to 5 microns thin slices are then spread on slides. After paraffin dissolution, then rehydration, the tissue is colored. The coloration associate a basic nuclear colorant (hematoxylin) and an acid colorant (eosin). The colored slice is protected with a glued glass or a transparent plastic film and is ready for histological analysis. The reading on the optic microscope brand Leica microsystems CMS Gmbh Ernest-Leitz-straBe 17-37 allowed the diagnosis.

4) Ethics considerations: The study was approved by the Ethical Committees of Lubumbashi's University. For Ethics and code of practice reasons and trying to avoid stigma, data were collected in such a manner that patients remained anonymous after obtaining their consent.

\subsection{Datas Statistics Analysis Technique}

Different datas collected were coded then captured on a computer and statistical analysis were performed on Microsoft Excel 2010 for encoding of datas and Epi Info $7^{\circledR}$ for determining frequencies.

\section{Results}

In our study, the diagnosis of superficial lymphadenopathy was made on 36 patients and Table 1 shows us characteristics of superficial lymphadenopathy patients.

Table 1. Superficial lymphadenopathy patients characteristics.

\begin{tabular}{|c|c|c|}
\hline Variable & Effective ( $\mathrm{n}=36$ ) & Percent \\
\hline \multicolumn{3}{|l|}{ Gender } \\
\hline Female & 13 & 36.1 \\
\hline Male & 23 & 63.9 \\
\hline \multicolumn{3}{|l|}{ Age } \\
\hline$<20$ years & 3 & 8.4 \\
\hline 20 - 29 years & 8 & 22.4 \\
\hline 30 - 39 years & 4 & 11.2 \\
\hline $40-49$ years & 11 & 30.8 \\
\hline 50 - 59 years & 5 & 14 \\
\hline$\geq 60$ years & 5 & 14 \\
\hline \multicolumn{3}{|l|}{ Reason for consultation } \\
\hline Lymph node tumefaction & 27 & 75 \\
\hline Other complaints* & 9 & 25 \\
\hline \multicolumn{3}{|l|}{ Associated symptoms } \\
\hline General condition altered by fever & 22 & 61.1 \\
\hline Existence of visceromegaly & 13 & 36.1 \\
\hline HIV serology & 10 & 27.8 \\
\hline \multicolumn{3}{|l|}{ Pathology diagnosis } \\
\hline Non-Hodgkin lymphoma & 17 & 47.2 \\
\hline Reactional hyperplasia & 10 & 27.8 \\
\hline Infectious lymphadenopathy & 7 & 19.4 \\
\hline Hodgkin lymphoma & 1 & 2.8 \\
\hline Undifferentiated & 1 & 2.8 \\
\hline
\end{tabular}

*Others complaints: Abdominal pain, fever, cough, nasal bleeding. 
This table shows that male patients consulted more (63.9\%) compare to female patients giving a sex ratio of 1.76 in favour of male gender. The group of age between 40 and 49 is the most predominant and the mean age of these patients was $42.47 \pm 15.64$ years with extremes from 17 to 83 years old. $75 \%$ of patients who were coming for consultation complained mainly of one or more lymph nodes tumefaction. On physical examination, $61.1 \%$ of patients had a general condition altered by fever and $36.1 \%$ of them had one visceromegaly (hepatomegaly, splenomegaly or both at the same time).

27.80\% of patients had a positive HIV serology. Non-Hodgkin lymphoma, lymph node reactive hyperplasia and infectious lymphadenopathy are pathologic diagnosis mostly encountered in our series with proportion of respectively $47.20 \%, 27.80 \%$ and $19.40 \%$.

Figure 1 and Figure 2 describe respectively location and clinical characteristics of superficial lymphadenopathy seen in our patients

Figure 1 shows location that cervical lymphadenopathy is most frequent (72.2\%) with combined form and $2.8 \%$ of patients had generalized lymphadenopathy.

Figure 2 shows that $88.9 \%$ of lymphadenopathy were mobile, $66.7 \%$ were hard in consistency and $41.7 \%$ presented pain on palpation.

\section{Discussion}

During this study, datas of 36 patients with superficial lymphadenopathy were captured. Among these, 23 were male and 13 were female with a sex ratio of 1.76 in favour of male. This demonstrates predominance of male patients in our sampling which seems to be confirmed by a numerous literature [9] [12]-[21] and in proportions ranging from 1.2 to 1.7. Nevertheless, some authors seem to report female predominance [22]-[24].

Even though our findings are similar to those of the first group of authors, it seems difficult to confirm any predominance of the gender because superficial lymphadenopathy has diverse aetiologies as said by Bazemore

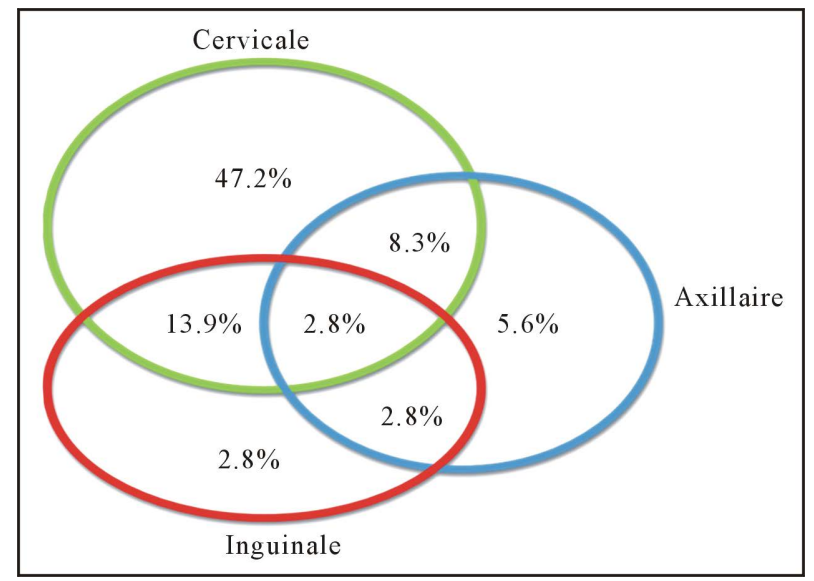

Figure 1. Location of superficial lymphadenopathy.

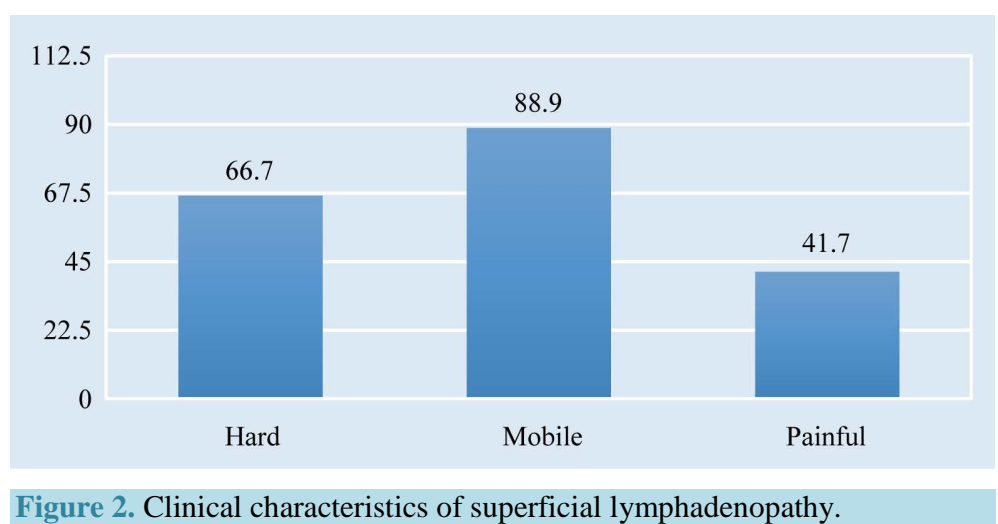

Figure 2. Clinical characteristics of superficial lymphadenopathy. 
[4] and Mosheni [5] in their studies and this pathology has different sex ratios depending on their aetiology. However, Lukic in a literature review on superficial lymphadenopathy report that male gender was a predictive factor for malignancy with relative risk estimated at 2.72 [25].

According to Karnath, multiple key factors should be considered to evaluate patients with superficial lymphadenopathy, including age in particular. In our study, the age group between 40 and 49 years old (30.8\%) was the most preponderant and the mean age for our patients was 41.47 years \pm 15.64 with extremes from 17 to 83 years. The mean age in our study is sensibly higher compared to majority of studies done [15] [19] [23] [26][28]. However, Chau in Britain have noticed a mean age of 40 years in patients with lymphadenopathy; proportion closer to our results [24]. We do not find patterns that can explain these results.

Lymph nodes tumefaction was the main reason for consultation in our study (75\%). Abba had, in their study in internal medicine department at Riyad Medical Complex in Saudi Arabia, found that 39\% of cases had lymph node tumefaction as the reason for consultation [23]. Diallo reported almost identical figures to Abba just that he didn't consider patients with seropositivity to HIV [27]. Our study shows that lymph nodes tumefaction is the chief complaint for patients with superficial lymphadenopathy (75\% of cases). We believe these results would explain the importance an anodin lymph node tumefaction on the body could illicit. Importance justified by the ignorance of the prognosis of the tumor that could be benign or malignant and maybe for aesthetics reasons when located on the neck.

With regard to our patients general condition, this was altered by fever in $61.1 \%$ of cases in our study and Ndongo in Senegal reported that fever was present in $89.4 \%$ of his patients [15]. Even though other authors recognize that fever might be present in patients with superficial lymphadenopathy, they believe that its presence wouldn't be as frequent as Ndongo observation had suggested [21] [23]. However, some literatures justify the presence of fever in these patient by the fact that this later would be one of signs of natural progression of two principal causes of superficial lymphadenopathy: tuberculosis and lymphoma; and this more particularly in cervical lymphadenopathy [29]-[31].

Appearance of splenomegaly associated or not with hepatomegaly in the presence of superficial lymphadenopathy is often rare [32]. Our study's found that visceromegalieswere present in $22.9 \%$. Abba and Ndongo had found respectively $22.7 \%$ and $36.7 \%$ [15] [23]. However, multiple literatures say that the presence of splenomegaly associated with hepatomegaly is often found in malignant non-Hodgkin lymphoma and acute leukemia [24] [29] [33].

Our study report a seroprevalence to HIV of $27.8 \%$ in our patients with superficial lymphadenopathy. These results compared to Mohan in South India (8\%) are very high [28]. In fact acquired immunodeficiency syndrome (AIDS) [34]. Although HIV can infect several tissues and organs, there are two main sites of infection predilection: the immune system and the central nervous system [35]. Superficial lymphadenopathy are early manifestation of HIV infection [36] and other authors believe that they should be regarded as an opportunistic manifestation of HIV infection [37]. Our results challenges us because HIV is still frowned upon in our environment and the efforts put in place to have a free treatment, acceptance of the disease is still very difficult. It would therefore be necessary to conduct a systematic serological screening in HIV-patients with superficial lymph nodes during our consultations.

Whether they are localized or generalized, superficial lymphadenopathy are part of symptoms of variable pathologies: "MIAMI” (Malignant, Infectious, Autoimmune, Miscellaneous/unusual, Iatrogenic) [4] for some and "CHICAGO" (Cancer, Hypersensitivity syndromes, Infectious, Connective tissue disorders, Atypical lymphoproliferative disorders, Granulomatous, Others) for others [5]. In our study, 47.2\% of patients with superficial lymphadenopathy has an as most frequent pathology diagnosis, non-Hodgkin lymphoma followed by reactive hyperplasia (27.8\%) and infectious lymphadenopathy (19.4\%) from which $85.7 \%$ were tuberculosis lymphadenopathy. A study done in Sub-Saharan Africa, showed that non-Hodgkin lymphoma is the 4th most frequent cancer responsible of death after cervix, liver and prostate cancer [42]. We believe that these should most attract our attention to the fact that cancer is a scourge whose impact is growing rapidly and is responsible for 7.6 million deaths worldwide [42]. However, studies done across different continents showed that tuberculosis would be the most frequent cause [16] [17] [28] [38]-[43]. On the other hand, Arun, in his study done in tertiary hospital in India reported that the most frequent cause was neoplasia lesions in $53 \%$ of cases and more than $50 \%$ of these lesions were non-Hodgkin lymphoma (32.1\% of all of the analyzed sample) [9].

This reinforce our opinion based on the fact that the biopsy remain a key element in the prognosis of superficial lymphadenopathy. Thus, the National Program against Tuberculosis (NTP) in the Democratic Republic of 
Congo, in particular, the diagnosis of tuberculous lymphadenitis is selected based on the clinical picture marked by chronic lymphadenopathy, a biological assessment (leukocyte formula lymphocytic trend) and conclusive tuberculosis treatment [44]; should be based on lymph node biopsy as a certainty diagnosis for superficial lymphadenopathy in order to ensure better management of these patients and to make a good rationalization in the management anti tuberculosis drugs.

\section{Conclusion}

36 patients were identified in our study and the most common etiology met in this series is non-Hodgkin lymphoma (47.2\%) followed by reaction nodal hyperplasia (27.8\%) and infectious lymphadenitis. The lymph node biopsy is important in confirming the diagnosis of superficial lymphadenopathy. Thus, it would be useful to consider this diagnosis means as an indispensable element in the confirmation of the aetiology of lymphadenopathy, even for resource-limited countries like the Democratic Republic of Congo to improve the management and prognosis of patients with superficial lymphadenopathy.

\section{Author's Contribution}

KC, MC conceived and designed the study. KC, KE, KM, KV conducted and collected data. KC, MO, MM, MC contribute to data analysis, interpretation and manuscript review. KC, MM, TB wrote manuscript.

\section{Conflicts of Interests}

The authors declare they have no competing interests.

\section{References}

[1] Abba, A.A. and Khalil, M.Z. (2012) Clinical Approach to Lymphadenopathy. Annals of Nigeria Medicine, 6, 11-17. http://dx.doi.org/10.4103/0331-3131.100201

[2] Boko, E. and Napo-Koura, G. (2005) Aspects épidémiologiques et antomopathologiques des lymphadenopathies bénignes diagnostiquées au laboratoire d'anatomie pathologique du CHU de Lomé. Lettre d'Oto-rhino-laryngologie et de chirurgie cervico-faciale $\mathrm{N}^{\circ} 297$ Mars-Avril.

[3] Ferrer, R. (1998) Lymphadenopathy: Differential Diagnosis and Evaluation. American Family Physician, 58, 13131320.

[4] Bazemore, A.W. and Smucker, D.R. (2002) Lymphadenopathy and Malignancy. American Family Physician, 66, 2103-2111.

[5] Mohseni, S., Shojaiefard, A., Khorgami, Z., Alinejad, S., Ghorbani, A. and Ghafouri, A. (2014) Peripheral Lymphadenopathy: Approach and Diagnostic Tools. Iranian Journal of Medical Sciences, 39, 158-170.

[6] Fijten, G.H. and Blijham, G.H. (1988) Unexplained Lymphadenopathy in Family Practice. An Evaluation of the Probability of Malignant Causes and the Effectiveness of Physicians’ Workup. Journal of Family Practice, 27, 373-376.

[7] Fontanilla, J.M., Barnes, A. and Fordham Voreyn, C. (2011) Current Diagnosis and Management of Peripheral Tuberculous Lymphadenitis. Clinical Infectious Diseases, 84, 350-362.

[8] Adeniji, K.A. and Anjorin, A.S. (2000) Peripheral Lymphadenopathy in Nigeria. African Journal of Medicine and Medical Sciences, 29, 233-237.

[9] Arun, R., Rakhec, K., Debdatta, B. and Bhawana, A.B. (2013) Spectrum of Histopathologic Diagnosis of Lymph Node Biopsies: A Descriptive Study from a Tertiary Care Center in South India over 5 1/2 Years. Indian Journal of Pathology and Microbiology, 56, 103-108. http://dx.doi.org/10.4103/0377-4929.118692

[10] Sibanda, E.N. and Stanczuck, G. (1993) Lymph Node Pathology in Zimbabwe: A Review of 2194 Specimens. QJM: An International Journal of Medicine, 86, 811-847.

[11] Moore, S.W., Scheinder, J.W. and Schaaf, H.S. (2003) Diagnostic Aspects of Cervical Lymphadenopathy in Children in the Developing World: A Study of 1877 Surgical Specimens. Pediatric Surgery International, 19, 240-244. http://dx.doi.org/10.1007/s00383-002-0771-x

[12] Ahmed, N., Israr, S. and Ashraf, M.S. (2009) Comparison of Fine Needle Aspiration Cytology (FNAC) and Excision Biopsy in the Diagnosis of Cervical Lymphadenopathy. Pakistan Journal of Surgery, 25, 72-75.

[13] Ochicha, O., Edino, S.T., Mohammed, A.Z., Umar, A.B. and Atanda, A.T. (2007) Pathology of Peripheral Lymph Node Biopsies in Kano, Northen Nigeria. Annals of African Medicine, 6, 104-108. 
http://dx.doi.org/10.4103/1596-3519.55725

[14] Shretstha, A.K., Chalise, P.R. and Sherstha, M.L. (2009) Lymph Node Biopsies: A Hospital Retrospective Study. Journal of Nepal Medical Association, 48, 306-309.

[15] Ndongo, S., Ndiaye, F.S., Vickola, J.A., Sougou, M.S., et al. (2008) Profil étiologique des adénopathies cervicales en Médecine Interne: Etude de 66 observations à Dakar (Sénégal). Méd Trop, 68, 523-527.

[16] Olu-Eddo, A.N. and Ohakana, C.E. (2006) Peripheral Lymphadenopathy in Nigeria Adults. Journal of Pakistan Medical Association, 56, 405-408.

[17] Adeniji, K.A. and Anjorin, A.S. (2000) Peripheral Lymphadenopathy in Nigeria. African Journal of Medicine and Medical Science, 29, 233-237.

[18] Getachew, A., Demissie, M. and Gemechu, T. (1999) Pattern of Histopatologic Diagnosis of Lymph Node Biopsies in a Teaching Hospital in Addis Ababa, 1981-1990 GC. Ethiopian Medical Journal, 37, 121-127.

[19] Darré, T., Amégbor, K., Sonhaye, L., Bissa, H., Pegbessou, E., et al. (2012) Profil histo-épidémiologique des adénopathies cervicales. A propos de 386 cas d’adénopathies cervicales a observées au CHU de Lomé. Médecine d'Afrique noire, 59, 563-567.

[20] Ageep, A.K. (2012) Assessment of Adult Peripheral Lymphadenopathy in Red Sea State, Sudan. International Journal of Tropical Disease \& Health, 2, 24-32. http://dx.doi.org/10.9734/IJTDH/2012/1008

[21] Diallo, D., Ouattara, A., Traore, H.A., Sidibe, A.T., Cisse, M.A. et al. (1994) Etiologies actuelles des adénopathies en médecine interne au Mali. Place de l'infection par le VIH. Médecine d'Afrique noire, 41, 89-93.

[22] Bosch, X., Coloma, E., Donate, C., Colomo, L., Doti, P., Jordan, A. and Lopez-Soto, A. (2014) Evaluation of Unexplained Peripheral Lymphadenopathy and Suspected Malignancy Using a Distinct Quick Diagnostic Delivery Model. Medicine, 93, e95. http://dx.doi.org/10.1097/md.0000000000000095

[23] Abba, A.A., Bamgboye, A.E., Afzal, M. and Rahmatullah, R.A. (2002) Lymphadenopathy in Adults. A Clinicopathological Analysis. Saudi Medical Journal, 23, 282-286.

[24] Chau, I., Keheller, M.T., Cunningham, D., Norman, A.R., et al. (2003) Rapid Access Multidisciplinary Lymph Node Diagnostic Clinic: Analysis of 550 Patients. British Journal of Cancer, 88, 354-361. http://dx.doi.org/10.1038/sj.bjc.6600738

[25] Lukic, S., Marjanovic, G. and Zivanovic, J. (2011) Palpable Lymphadenopathy in Primary Care. Scientific Journal of the Faculty of Medecine in Nis, 28, 17-23.

[26] Boko, E. and Napo-Koura, G. (2005) Aspects épidémiologiques et anatomopathologiques des lymphadénopathies bénignes diagnostiquées au laboratoire d'anatomie pathologique du CHU de Lomé. La Lettre d'Oto-rhino-laryngologie et de chirurgie cervico-faciale, 297, 23-25.

[27] Kumar, N., Gupta, B.B., Sharma, B., Kaushal, M., Rewari, B.B. and Sundriyal, D. (2014) Role of Fine-Needle Cytology in Human Immunodefisciency Virus-Associated Lymphadenopathy: A Cross-Sectional Study from Northern India. Hong Kong Medical Journal, 21, 38-44.

[28] Mohan, A., Reddy, M.K., Phaneedra, B.V. and Chandra, A. (2007) Aetiology of Peripheral Lymphadenopathy in Adults: Analysis of 1724 Cases seen at a Tertiary Care Teaching Hospital in Southern India. The National Medical Journal of India, 20, 78-80.

[29] Kinde-Gazard, D., Anagonou, Y.S., Gninafon, M., Tawo, L. and Josse, R. (1997) Les adénopathies cervicales d'origine tuberculeuse: aspects épidémiologiques, diagnostiques et thérapeutiques. Médecine d'Afrique noire, 44, 90-94.

[30] Centwoski, P., Sawsezuk-Chabin, J., Prochoree, M. and Warzocha, K. (2005) Hodgkin’s Lymphoma and Tuberculosis Coexistence in Cervical Lymph Node. Leuk Lymphoma, 46, 471-475. http://dx.doi.org/10.1080/10428190400019891

[31] Wahab, M.F., El-Gindy, I.M. and Fathy, G.M. (1998) Screening Tests for Diagnosis of Cervical Lymphadenopathy Presenting as Prolonged Fever. The Journal of the Egyptian Public Health Association, 73, 538-562.

[32] Pangalis, G.A., Vassilakopoulos, T.P., Boussiotis, V.A. and Fessas, P. (1993) Clinical Approach to Lymphadenopathy. Seminars in Oncology, 20, 570-582.

[33] Habermann, T.M. and Steensma, D.P. (2000) Lymphadenopathy. Mayo Clinic Proceedings, 75, 723-732. http://dx.doi.org/10.1016/S0025-6196(11)64620-X

[34] Deshmuth, A.T., Jagtap, M.W. and Nomaan, N. (2013) Cytological Evaluation of Lymphadenopathy in HIV Patients. International Journal of Recent Trends Science and Technology, 6, 125-129.

[35] Kumar, V., Abbas, A.K., Fausto, N., et al. (2010) Disease of Immune System, 8th Sauth Asia Edition, Elsevier Publication, Amsterdam, 235-249.

[36] Kumarguru, B.N., Kulkarni, M.H. and Kamaken, N.S. (2009) FNAC of Peripheral Lymph Node in HIV Positive Patients. Scientific \& Medical, 1, 4-12. 
[37] Vanisri, H.R., Nandini, N.M. and Sunila, R. (2008) Fine-Needle Aspiration Cytology Findings in Human Immunodeficiency Virus Lymphadenopathy. Indian Journal of Pathology and Microbiology, 51, 481-484. http://dx.doi.org/10.4103/0377-4929.43735

[38] Bem, C., Patil, P.S. and Luo, N. (1996) The Increased Burden of Tuberculous Lymphadenitis in Central Africa: Lymph node Biopsies in Lusaka, Zambia, 1981 and 1990. Tropical Doctor, 26, 58-61.

[39] Pernboom, R.M., Ritcher, C., Swai, A.B., Kitinya, J., et al. (1994) Diagnosis of Tuberculous Lymphadenitis in an Area of HIV Infection and Limited Diagnostic Facilities. Tropical and Geographical Medicine, 46, 288-292.

[40] Bottles, K., McPhaul, L.W. and Volberding, P. (1988) Fine-Needle Aspiration Biopsy of Patients with Acquired Immunodeficiency Syndrome (AIDS): An Experience in an Outpatient Clinic. Annals of Internal Medicine, 108, 42-45. http://dx.doi.org/10.7326/0003-4819-108-1-42

[41] Bayazit, Y.A., Bayazit, N. and Nadimuru, M. (2004) Mycobacterial Cervical Lymphadeitis. Journal for Oto-RhinoLaryngology and Its Related Specialties, 66, 275-280. http://dx.doi.org/10.1159/000081125

[42] Sylla, B.S. and Wild, C.P. (2012) A Million Africans a Year Dying from Cancer by 2030: What Can Cancer Research and Control Offer to the Continent? International Journal of Cancer, 130, 245-250. http://dx.doi.org/10.1002/ijc.26333

[43] Wright, C.A., Warren, R.M. and Marais, B.J. (2009) Fine Needle Aspiration Biopsy: An Undervalued Diagnostic Modality in Paediatric Mycobacterial Disease. International Journal of Tuberculosis and Lung Disease, 13, 1467-1475.

[44] Programme National de Lutte contre la Tuberculose (2014) Guide de prise en charge de la tuberculose PATI 5. Édition 2014, Kinshasa.

\section{Abbreviations}

DRC: Democratic Republic of Congo

HIV: Human Immunodeficiency Virus

ELISA: Enzyme-Linked Immunosorbent Assay

\section{Warmly welcome your paper submission to OALib Journal!}

- Publication on a daily basis

- 9 subject areas of science, technology and medicine

- Fair and rigorous peer-review system

- Fast publication process

- Article promotion in various social networking sites (LinkedIn, Facebook, Twitter, etc.)

- Widely-targeted and multidisciplinary audience to read your research

Submit Your Paper Online: $\underline{\text { Click Here to Submit }}$

Contact Us: service@oalib.com 